\title{
Skrining Ketajaman Penglihatan pada Siswa SDN
}

\author{
Hanna Nurul Husna, Chita Widia \\ ${ }^{1)}$ Program Studi Refraksi Optisi STIKes Bakti Tunas Husada Tasikmalaya \\ Email: hanna.nurulhusna@gmail.com
}

\begin{abstract}
Abstrak
Gangguan pada mata akan menyebabkan gangguan penglihatan yang berdampak pada ketidaknyamanan dan gangguan lainnya dalam menjalani aktivitas sehari-hari. WHO menyatakan sebanyak 19 juta anak-anak yang berusia di bawah 15 tahun diperkirakan mengalami gangguan penglihatan dan 12 juta di antaranya disebabkan oleh kelainan refraksi mata. Kegiatan pengabdian masyarakat ini merupakan salah satu bentuk dukungan terhadap Peta Jalan Penanggulangan Gangguan Penglihatan 2017-2030 dan salah satu upaya dalam mencegah gangguan penglihatan pada anak. Kegiatan yang dilakukan adalah skrining pemeriksaan visus ataupun koreksi bagi siswa SD kelas 3 dan 4 yang disertai dengan pemberian informasi mengenai pentingnya menjaga kesehatan mata dan melakukan. Tujuan dari skrining visus ini adalah untuk mengetahui gambaran kelainan refraksi mata pada siswa SD. Lokasi skrining kelainan refraksi dilaksanakan di SDN 1 Cikalang Kecamatan Tawang Kota Tasikmalaya. Subjek adalah siswa kelas 3 dan 4 dalam rentang umur 8-9 tahun yang diduga tidak mengalami kelainan refraksi. Skrining visus dilakukan dengan menggunakan Optotipe Snellen dan dikoreksi dengan menggunakan lensa coba/trial lens. Pelaksanaan kegiatan pengabdian masyarakat ini berlangsung dengan lancar dan efisien. Pada siswa kelas 3 (8-9 tahun) terdapat 10 siswa (24\%) yang mengalami kelainan refraksi, kelas 4A (9-10 tahun) terdapat 8 siswa (20\%) yang mengalami kelainan refraksi, dan di kelas 4B terdapat 6 siswa (14\%) yang mengalami kelainan refraksi. Kegiatan ini diharapkan dapat menumbuhkan motivasi dan kesadaran siswa dan orang tua untuk melakukan pemeriksaan rutin pada mata sejak dini.
\end{abstract}

Kata Kunci : Kelainan refraksi, kesehatan mata, skrining.

\begin{abstract}
Eye disturbance causes visual impairment, which could make inconvenience in daily activities. WHO stated 19 million children under 15 years old experience visual impairment and 12 million of them were caused by refractive error. Prodi Refraksi Optisi STIKes BTH's community engagement was one of action to support "Prevention of Visual Impairement Road Map 2017-2030", and also in order to prevent visual impairement to children. The activities were given for 3 and $4^{\text {th }}$ grade student of SDN 1 Cikalang Kecamatan Tawang Kota Tasikmalaya, such as visual refractive examination and visus correction, and followed by eye health counseling. The Optotipe Snellen was used for visual examination and corrected using trial lens. This community enggagement held smoothly and efficient. There are 10 students of grade 3th; 8 students of grade 4th class A; and 10 students of grade 4th class $B$ who experience refractive disorder. Hope this community enggagement would grow students' motivation and parents' awareness to perform eye examination periodically start from young ages.
\end{abstract}

Keywords : Eye health, refractive disorder, screening.

\section{Pendahuluan}

Mata merupakan salah satu indera yang sangat penting dalam menunjang kehidupan. Gangguan pada mata akan menyebabkan gangguan penglihatan yang berdampak pada ketidaknyamanan dan gangguan lainnya dalam menjalani aktivitas sehari-hari.

Gangguan penglihatan menjadi masalah yang mendapat banyak perhatian, tidak hanya di Indonesia tapi juga di dunia. Berdasarkan laporan World Health Organization [WHO] (2017) diketahui bahwa penyebab gangguan penglihatan terbanyak di seluruh dunia adalah gangguan refraksi yang tidak terkoreksi sebesar 53\%, katarak yang tidak dioperasi sebesar 25\%, dan degenerasi macular sebesar 4\%. Indonesia mempunyai prevalensi kebutaan dan gangguan penglihatan nomor 2 tertinggi di dunia setelah Ethiopia (Karfiati, n.d). Gangguan penglihatan dan 
kebutaan di Indonesia mengalami peningkatan dengan prevalensi 1,5\% dan tertinggi dibandingkan dengan angka kebutaan di negara-negara regional Asia Tenggara seperti Bangladesh sebesar 1\%, India sebesar 0,7\%, dan Thailand 0,3\% (Fauzi, Anggorowati, \& Heriana, 2016). Hasil Survei Kebutaan Rapid Assessment of Avoidable Blindness (RAAB) tahun 2014-2016 di 15 provinsi menunjukkan penyebab utama gangguan penglihatan dan kebutaan adalah katarak 70-80\% dan kelainan refraksi 10-15\% (Kementerian Kesehatan RI, 2013).

Kelainan refraksi merupakan gangguan penglihatan yang sering terjadi pada seseorang. Kelainan ini terjadi ketika seseorang tidak bisa melihat secara jelas dan fokus pada jarak dekat ataupun jarak jauh. Kelainan refraksi ini bisa berdampak pada melemahnya penglihatan/visual impairment. WHO (2017) mengelompokkan pelemahan penglihatan menjadi kategori: penglihatan normal (normal vision), pelemahan penglihatan sedang (moderate visual impairment), pelemahan penglihatan berat (severe visual impairment), dan kebutaan (blindness). Menurut WHO (Fauzi, Anggorowati, \& Heriana, 2016), sebanyak 19 juta anak-anak yang berusia di bawah 15 tahun diperkirakan mengalami gangguan penglihatan dan 12 juta di antaranya disebabkan oleh kelainan refraksi mata, suatu kondisi yang seharusnya mudah untuk didiagnosis dan diperbaiki.

Berdasarkan teori kesehatan masyarakat (Suyasa, Rahayuni, Ariani, \& Harditya, 2017) terdapat empat metode penanganan masalah kesehatan di masyarakat yaitu upaya promotif, preventif, kuratif dan rehabilitatif. Upaya promotif adalah upaya pembelajaran masyarakat dari, untuk dan oleh masyarakat untuk meningkatkan derajat kesehatannya. Upaya preventif adalah suatu upaya untuk mencegah terjadinya penyakit maupun masalah kesehatan yang tidak diinginkan. Upaya kuratif lebih mengarah ke pengobatan sedangkan upaya rehabilitatif lebih mengarah kepada hal-hal yang bersifat pemulihan. Dari keempat metode tersebut, upaya promotif dan preventif merupakan upaya yang lebih cocok dilakukan untuk mencegah terjadinya masalah kesehatan di masyarakat. Upaya promotif preventif lebih menekankan pada kesadaran masyarakat tentang pentingnya kesehatan dan dampaknya pun akan dirasakan dalam waktu yang singkat.

Upaya promotif dan preventif dalam menanggulangi masalah gangguan penglihatan, yang dilakukan pemerintah dalam hal ini Kementerian Kesehatan, meluncurkan Peta Jalan (Road Map) Penanggulangan Gangguan Penglihatan 2017-2030 (Kementerian Kesehatan RI, 2017), dengan langkah strategis antara lain: 1) menjamin anak sekolah dengan gangguan penglihatan dapat terkoreksi, 2) mengembangkan pola pelayanan kesehatan komprehensif penderita retinopati diabetikum, glaukoma dan low vision, dan 3) mengembangkan konsep rehabilitasi penglihatan yang komprehensif dan inklusif.

Program Studi Refraksi Optisi STIKes Bakti Tunas Husada Tasikmalaya merupakan salah satu perguruan tinggi kesehatan di Indonesia yang mencetak tenaga-tenaga refraksionis optisien yang ahli di bidang kesehatan mata. Sebagai bentuk partisipasi dan dukungan Prodi Refraksi Optisi terhadap Peta Jalan Penanggulangan Gangguan Penglihatan 2017-2030, terutama langkah nomor 1, 
dan juga sebagai bentuk pelaksanaan Tridarma Perguruan Tinggi, maka kami melakukan kegiatan pengabdian masyarakat dalam bentuk penyuluhan kesehatan mata dan skrining ketajaman penglihatan/visus pada anak-anak SD.

Kegiatan pengabdian masyarakat yang dilaksanakan oleh Program Studi Refraksi Optisi ini merupakan salah satu bentuk dukungan terhadap Peta Jalan Penanggulangan Gangguan Penglihatan 2017-2030 dan salah satu upaya dalam mencegah gangguan penglihatan pada anak sejak dini. Kegiatan yang dilakukan adalah memberikan informasi mengenai pentingnya menjaga kesehatan mata dan makanan yang sehat bagi mata sehat serta memberikan pelayanan pemeriksaan tajam penglihatan (visus) ataupun koreksi bagi siswa SD kelas 3 dan 4.

Kegiatan pemberian informasi kesehatan mata dilakukan untuk memberikan informasi kepada seluruh warga sekolah mengenai langkah-langkah menjaga kesehatan mata serta makanan yang harus dikonsumsi untuk menjaga kesehatan mata. Sedangkan skrining visus dilakukan untuk mengetahui gambaran kelainan refraksi pada siswa SD. Skrining visus sebagai bentuk deteksi dini yang dapat menjadi salah satu langkah awal dalam mencegah gangguan penglihatan anak. Setiap anak harus mendapatkan pemeriksaan mata secara rutin setiap 6 bulan sekali dimulai sejak dini. Skrining visus ini sendiri direkomendasikan WHO (Juneti, Bebasari, \& Nukman, 2015) sebagai cara yang efektif untuk mendeteksi gangguan penglihatan pada anak secara dini. Kegiatan utama pada pengabdian masyarakat ini adalah skrining visus, dan pemberian informasi kesehatan mata dilakukan sebagai pendukung dalam kegiatan ini.

\section{Metode}

Populasi skrining adalah siswa SD dengan kisaran umur 6-11 tahun di Kecamatan Tawang Kota Tasikmalaya. Wilayah ini dipilih karena dekat dengan kampus STIKes BTH Tasikmalaya dan diketahui bahwa di daerah dan sekolah ini belum pernah dilaksanakan pemeriksaan ketajaman penglihatan/visus dalam rentang waktu 6 bulan terakhir.

Lokasi kegiatan pengabdian masyarakat dilaksanakan di SDN 1 Cikalang Kecamatan Tawang Kota Tasikmalaya. Subjek penyuluhan dan skrining adalah siswa kelas 3 dan 4 dalam rentang umur 8-9 tahun yang diduga tidak mengalami kelainan refraksi. Konfirmasi tersebut diketahui berdasarkan informasi dari wali kelas bahwa sekolah belum pernah menerima pemeriksaan kesehatan mata selama 6 bulan terakhir dan juga berdasarkan hasil observasi bahwa tidak ada siswa yang memakai kacamata. Jumlah siswa yang menjadi subjek adalah 116 orang.

Kegiatan pengabdian masyarakat dilaksanakan oleh seluruh sivitas akademika Prodi Refraksi Optisi meliputi dosen, laboran, dan mahasiswa. Pelaksanaan pemeriksaan visus dilakukan oleh mahasiswa calon optisien dengan pengawasan refraksionis optisien. Kegiatan pemberian informasi 
kesehatan mata dilakukan oleh dosen dan mahasiswa. Penyediaan alat-alat penyuluhan dan pemeriksaan disediakan oleh STIKes BTH Tasikmalaya.

Kegiatan pengabdian yang dilakukan adalah pemberian informasi kesehatan mata dan skrining visus. Untuk memenuhi standar ruangan pemeriksaan refraksi maka kelas telah diatur terlebih dahulu saat tim pengabdian masuk ke kelas. Pengaturan yang dilakukan seperti penempatan meja pendaftaran, penempatan Optotipe Snellen, penempatan Lensa Coba, dan penempatan Lensometer. Hal ini dilakukan agar saat kegiatan skrining akan dilakukan, persiapan peralihannya dari sesi penyuluhan tidak memakan waktu lama untuk setting tempat.

Kegiatan yang pertama kali dilakukan adalah pembukaan yang dilanjutkan dengan pemberian informasi seputar kesehatan mata sebelum pemeriksaan visus. Bentuk kegiatan ini mirip dengan penyuluhan kesehatan mata, tapi tanpa disertai dengan pretest dan posttest. Metode pemberian informasi kesehatan mata yang digunakan adalah metode ceramah dan pendampingan dengan memberikan informasi kesehatan kepada siswa dan guru mengenai langkah-langkah menjaga kesehatan mata dan makanan sehat bagi mata. Selain itu juga memotivasi dan mengajak seluruh warga sekolah untuk menjaga kesehatan matanya.

Setelah kegiatan pemberian informasi kesehatan mata selesai dilakukan, selanjutnya dilaksanakan pemeriksaan visus yang dilakukan oleh mahasiswa dengan menggunakan Optotipe Snellen. Hasil pemeriksaan visus tersebut kemudian dianalisis dan dikategorikan. Jika siswa didiagnosis mengalami kelainan refraksi, maka dilaksanakan koreksi dengan menggunakan lensa coba/trial lens. Hasil visus dan koreksi visus direkam dalam lembar resep dan selanjutnya dirangkum dalam tabel data pemeriksaan. Hasil visus siswa tersebut kemudian dilaporkan dan dikonsultasikan dengan wali kelas untuk dilakukan tindak lanjut.

\section{Hasil}

Kegiatan pengabdian masyarakat yang dilakukan adalah dalam bentuk pemberian informasi kesehatan mata dan pemeriksaan mata, dengan tema "Mata Sehat Generasi Muda Indonesia". Kegiatan pengabdian masyarakat dilaksanakan pada hari Sabtu, tanggal 18 Maret 2017. Kegiatan berjalan dengan lancar dan efisien. Karena keterbatasan waktu, kegiatan pemberian informasi kesehatan mata hanya berupa penyampaian informasi saja tanpa disertai pretest dan postest. Kegiatan lebih difokuskan pada kegiatan skring visus yang lebih banyak menghabiskan banyak waktu, yaitu skrining visus, konsultasi hasil, dan pelaporan.

Tim pengabdian masyarakat mengajukan surat izin dan proposal pengabdian kepada sekolah. Kepala sekolah menyambut baik dan memberikan izin untuk pelaksanaan kegiatan ini. Untuk pemilihan sasaran penyuluhan dan subjek pemeriksaan, kepala sekolah memberikan arahan untuk 
menggunakan siswa kelas 3 dan 4, dengan pertimbangan bahwa mereka cukup mandiri untuk menghadapi hal baru serta tidak dikejar oleh materi pembelajaran untuk menghadapi ujian negara.

Pelaksanaan pemberian informasi kesehatan mata dilakukan di kelas. Kegiatan dimulai dengan salam pembuka, perkenalan, pembagian brosur dan selanjutnya dilakukan pemberian informasi kesehatan mata oleh beberapa mahasiswa. Brosur informasi kesehatan mata yang dibagikan memuat rangkuman materi-materi kesehatan mata yang akan disampaikan. Hal ini bertujuan agar informasi bisa dibaca subjek dan orang lain dimanapun berada. Penyuluhan dilaksanakan secara interaktif dan dengan bahasa yang mudah dipahami oleh siswa. Siswa berpartisipasi aktif dalam kegiatan ini dan mengajukan beberapa pertanyaan mengenai hal-hal yang tidak mereka mengerti.

Materi pertama: cara-cara untuk menjaga kesehatan mata. Penglihatan yang normal dan sehat dapat terwujud jika organ mata berada dalam keadaan yang sehat. Di era digital ini, menjaga mata menjadi lebih sulit daripada sebelumnya. Hal ini dikarenakan penggunaan gadget yang berlebihan dan tidak bisa dipisahkan dari gaya hidup. Beberapa cara yang bisa dilakukan untuk menjaga kesehatan mata: diet yang seimbang, menghindari kebiasaan hidup yang buruk, rutin melakukan pemeriksaan mata, senam mata, mengetahui sejarah mata dalam keluarga, memakai pelindung mata, istirahat yang cukup, tidak menggosok atau mengucek mata terlalu kuat, tidak menyentuh mata dengan tangan kotor, menerapkan kebiasaan menonton TV dan membaca yang benar, mengubah lingkungan.

Materi kedua: makanan untuk mata yang sehat. Keadaan mata yang sehat tidak hanya bisa dicapai dengan mengubah pola perilaku dan lingkungan saja. Asupan gizi yang sesuai dengan kebutuhan mata merupakan hal yang sangat penting untuk diperhatikan. Beberapa makanan yang memiliki gizi yang baik untuk mata diantaranya: wortel, biji bunga matahari, ikan salmon, telur, bayam, alpukat, bawang putih, tomat, cokelat hitam, dan kol/brokoli.

Brosur yang digunakan dalam pemberian informasi kesehatan mata ini disajikan pada gambar 1 di bawah ini.

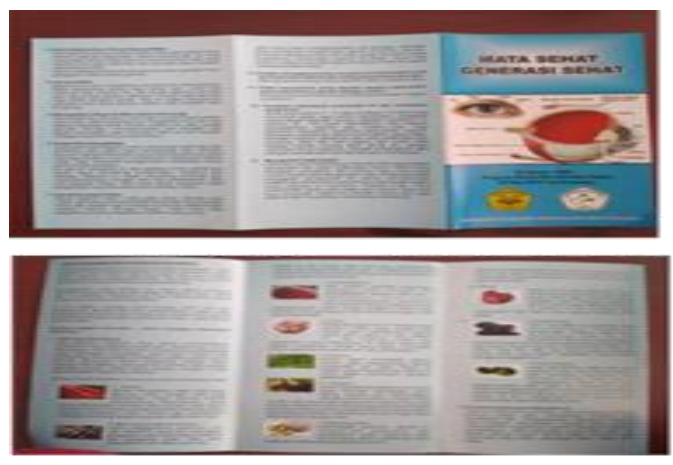

Gambar 1. Brosur kesehatan mata

Setelah kegiatan pemberian informasi kesehatan mata selesai dilaksanakan, siswa diarahkan untuk pelaksanaan skrining visus. Kegiatan ini menghabiskan alokasi waktu yang cukup banyak. 
Pertama, siswa diminta untuk melakukan pendaftaran untuk pendataan data diri yang direkam dalam lembar resep. Setelah pendaftaran, siswa diberikan tes buta warna. Hasil tes ini juga direkam dalam lembar resep. Setelah tes buta warna selesai dilakukan, siswa diarahkan ke tempat lain untuk diperiksa visus-nya. Siswa dikategorikan memiliki penglihatan normal jika siswa bisa membaca Optotipe Snellen sampai baris ke-8 dan hasil visus-nya 6/6. Angka "6" atas menunjukkan jarak pasien (siswa) dapat melihat huruf pada Snellen Chart, dan angka "6" bagian bawah menunjukkan jarak huruf tersebut dapat dilihat oleh orang normal. Siswa dikategorikan memiliki kelainan refraksi jika visus nya kurang dari itu, yaitu 6/7.5, 6/9, 6/12, 6/15, 6/18, 6/21. Bagi siswa yang memiliki kelainan refraksi, mahasiswa calon optisien - dengan pengawasan refraksionis optisien, langsung memberikan koreksi dengan menggunakan Lensa Coba. Dari tindakan koreksi ini diperoleh data mengenai kekuatan (power) lensa koreksi agar siswa bisa melihat maksimal sampai baris ke 8 Optotipe Snellen (visus 6/6). Data visus dan koreksi tersebut direkam dalam lembar resep. Datadata hasil pemeriksaan visus dan koreksi kemudian ditulis ulang di tabel data pemeriksaaan dan ditandai pada nama-nama siswa yang memiliki kelainan refraksi untuk dilaporkan pada wali kelasnya.

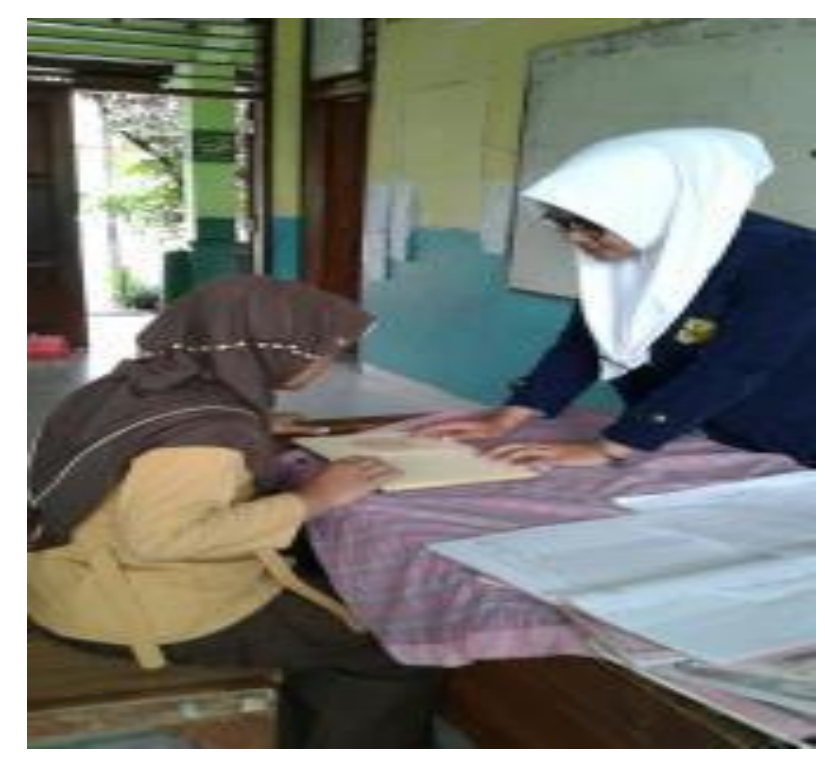

Gambar 2. Tahap pendaftaran dan pemeriksaan buta warna 

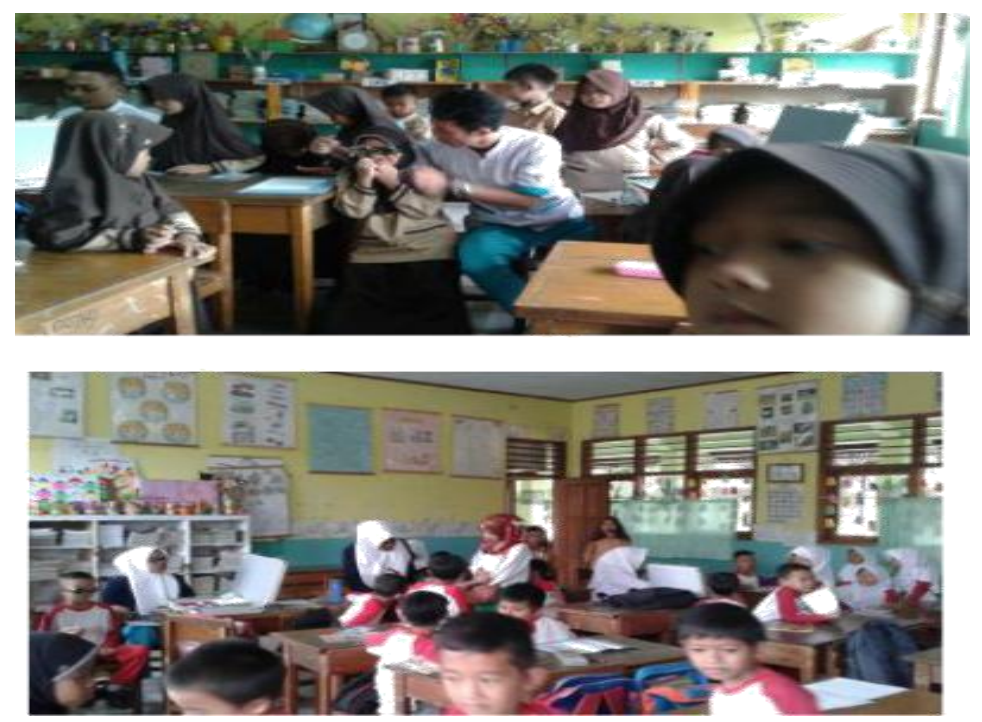

Gambar 3. Tahap pemeriksaan visus dan koreksi

Data hasil skrining kelainan refraksi pada siswa disajikan dalam tabel 1 di bawah ini.

\section{Tabel 1. Data Hasil Skrining Kelainan Refraksi}

\begin{tabular}{|c|c|c|c|c|c|}
\hline \multicolumn{6}{|c|}{ Jumlah Siswa } \\
\hline \multirow[t]{2}{*}{ Kelas } & \multicolumn{2}{|c|}{$\begin{array}{c}\text { Penglihatan } \\
\text { Normal }\end{array}$} & \multicolumn{2}{|c|}{$\begin{array}{l}\text { Kelainan } \\
\text { Refraksi }\end{array}$} & \multirow[t]{2}{*}{ Total } \\
\hline & fn & $\%$ & fn & $\%$ & \\
\hline 3 & 31 & 76 & 10 & 24 & 41 \\
\hline $4 \mathrm{~A}$ & 33 & 80 & 8 & 20 & 41 \\
\hline $4 \mathrm{~B}$ & 28 & 82 & 6 & 14 & 34 \\
\hline
\end{tabular}

Berdasarkan tabel 1 di atas dapat dilihat bahwa pada kelas 3 (8-9 tahun) terdapat 10 siswa (24\%) yang mengalami kelainan refraksi, kelas 4A (9-10 tahun) terdapat 8 siswa (20\%) yang mengalami kelainan refraksi, dan di kelas 4B terdapat 6 siswa (14\%) yang mengalami kelainan refraksi. Tindakan koreksi langsung diberikan pada siswa yang mengalami kelainan refraksi, tetapi tidak dilakukan pemeriksaan pin-hole. Hal inilah yang menjadi keterbatasan dalam pemeriksaan ini. Oleh karena itu, data hasil koreksi tajam penglihatan tidak ditampilkan dalam artikel ini.

Temuan dari pemeriksaan ini adalah bahwa jumlah anak di usia rendah (kelas 3) yang mengalami kelainan refraksi lebih banyak dibandingkan dengan anak di usia lebih tua (kelas 4). Beberapa faktor diduga menjadi penyebab peristiwa ini terjadi seperti ada anggota keluarga yang memiliki riwayat kelainan refraksi, kelainan biologis anak, gaya belajar siswa (seperti membaca di tempat gelap dengan posisi badan tengkurap atau terlalu dekat), serta intensitas penggunaan gadget yang tinggi dengan posisi yang tidak baik. 


\section{Pembahasan}

Pemeriksaan mata dengan menggunakan Optotipe Snellen sepertinya menjadi hal yang baru bagi siswa. Hal ini terlihat pada saat dilakukan pemeriksaan, banyak siswa yang menjadi tegang dan kaku. Banyak juga siswa yang digoda temannya karena tidak bisa membaca huruf yang ada di Snellen. Godaan ini kadang berujung dengan ejekan, dan siswa menjadi kurang kooperatif saat dilakukan pemeriksaan, karena mungkin mereka malu. Kejadian ini bisa berdampak pada ketepatan hasil pemeriksaan visus. Agar siswa mau kooperatif lagi terhadap pemeriksaan, siswa ditenangkan dan diberi penjelasan bahwa hal tersebut masih normal dan tidak apa-apa.

Setelah pemeriksaan visus selesai dilakukan, siswa diberikan konsultasi sekilas mengenai kondisi kesehatan mata mereka dan hal-hal yang harus mereka lakukan untuk menjaga dan meningkatkan kondisi mata mereka. Konsultasi kesehatan mata lebih lanjut dilakukan pada wali kelas siswa. Dosen dan Refraksionis Optisien melaporkan hasil pemeriksaan visus dan koreksi pada wali kelas sebagai bentuk tindak lanjut terhadap pemeriksaan yang telah dilakukan. Maksud dari pelaporan ini adalah sebagai pemberian informasi kepada wali kelas bahwa terdapat siswa yang memiliki kelainan refraksi. Karena pada umumnya siswa tidak menyadari bahwa dirinya mengalami kelainan refraksi sebelum pemeriksaan visus mata. Kalaupun ada ketidaknyamanan penglihatan di kelas, siswa belum bisa berbicara dengan bebas mengenai apa yang mereka rasakan. Pelaporan yang dilakukan meliputi hasil pemeriksaan visus, penyebab kelainan refraksi pada anak, serta kemungkinan treatment yang bisa dilakukan seperti: pemeriksaan mata ke fasilitas kesehatan terdekat, penggunaan kacamata dll.

Kelainan refraksi dapat mengganggu penerimaan informasi saat pembelajaran. Jika tidak ditangani dengan baik, kelainan refraksi dapat mempengaruhi prestasi belajar anak. Hal ini didukung oleh penelitian yang dilakukan oleh Rumondor \& Rares (2014) bahwa terdapat hubungan yang signifikan antara kelainan refraksi dengan prestasi belajar.

Wali kelas merespon dengan baik dengan hasil yang telah diperoleh. Mereka berterima kasih karena telah diadakan kegiatan pemeriksaan mata, dan akan mengkonsultasikannya dengan orang tua wali masing-masing murid yang mengalami kelainan refraksi untuk ditindak lanjuti. Kemampuan refraksi siswa akan berubah dan berkembang seiring dengan pertumbuhan usia (Fauzi, Anggorowati, \& Heriana, 2016). Jika terjadi kelainan refraksi saat anak-anak, besar kemungkinan pada dewasa nanti keadaan refraksi nya akan bisa berubah jika diobati. Akan tetapi, sesuai pepatah "Lebih baik mencegah daripada mengobati”, pengobatan dan deteksi dini merupakan langkah yang sangat tepat dilakukan pada siswa SD. Pemeriksaan visus di sekolah dapat dijadikan sebagai bentuk deteksi dini gangguan kelihatan pada siswa. Kegiatan ini diharapkan dapat menumbuhkan motivasi dan kesadaran siswa dan orang tua untuk melakukan pemeriksaan rutin pada mata sejak dini. 
Setelah dilaksanakannya kegiatan pengabdian pada masyarakat ini, penulis tertarik untuk melakukan kegiatan serupa di sekolah lainnya dengan berbagai latar belakang berbeda, khususnya sekolah yang jarang mendapatkan pelayanan pemeriksaan kesehatan mata dari puskesmas setempat. Antusiasme siswa di sekolah sangat memotivasi penulis dan tim dalam melaksanakan kegiatan ini.

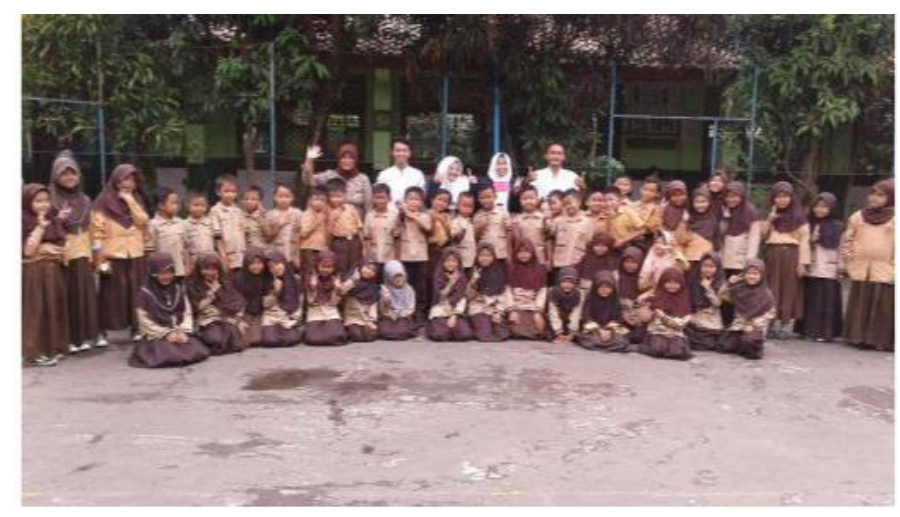

Gambar 4. Foto tim pengabdian beserta guru kelas dan siswa

Untuk kegiatan pengabdian selanjutnya, penulis tertarik untuk menggunakan media pemberian infoemasi yang lain (tidak sebatas brosur dan ceramah). Penulis juga tertarik untuk melakukan pelatihan pemeriksaan visus kepada guru dan kader cilik di sekolah sebagai bentuk deteksi dini kelainan refraksi yang terjadi di sekolah. Penulis juga mengharapkan kerjasama dengan instansi kesehatan terdekat dan dinas kesehatan kota Tasikmalaya agar dapat memberikan informasi lebih lanjut tentang kesehatan mata demi meningkatkan kualitas kesehatan mata di wilayah ini.

\section{Simpulan}

Pelaksanaan kegiatan pengabdian masyarakat ini berlangsung dengan lancar dan efisien. Pada siswa kelas 3 (8-9 tahun) terdapat 10 siswa (24\%) yang mengalami kelainan refraksi, kelas 4A (910 tahun) terdapat 8 siswa $(20 \%)$ yang mengalami kelainan refraksi, dan di kelas $4 \mathrm{~B}$ terdapat 6 siswa (14\%) yang mengalami kelainan refraksi. Kegiatan ini diharapkan dapat menumbuhkan motivasi dan kesadaran siswa dan orang tua untuk melakukan pemeriksaan rutin pada mata sejak dini.

\section{Daftar Pustaka}

Fauzi, L., Anggorowati, L., \& Heriana, C. (2016). Skrining Kelainan Refraksi Mata Pada Siswa Sekolah. Journal of Health Education, 1 ((1)), 76-84. Retrieved from http://journal.unnes.ac.id/sju/index.php/jhealthedu/.

Juneti, Bebasari, E., \& Nukman, E. (2015). Gambaran Faktor-Faktor Yang Mempengaruhi Gangguan Tajam Penglihatan Pada Anak Sekolah Dasar Kelas V Dan Kelas VI Di SDN 017 Bukit Raya Pekanbaru Tahun 2014. JOM FK, 2(2), 1-10. Retrieved July 29, 2018, from 
https://media.neliti.com/media/publications/184777-ID-gambaran-faktor-faktor-yangmempengaruhi.pdf.

Karfiati, F. (n.d.). Pusat Mata Nasional Rumah Sakit Mata Cicendo Bandung. Retrieved from Penanggulangan Gangguan Penglihatan Nasional: http://www.cicendoeyehospital.org/index.php/beranda/605-peringkat-iv-dari-60-pesertadiklatpim-ii-pgp-nasional.html.

Kementerian Kesehatan RI. (2013). InfoDatin, Situasi Gangguan Penglihatan dan Kebutaan. Jakarta: Kementerian Kesehatan RI. Retrieved Juli 28, 2018, from http://www.depkes.go.id/download.php?file=download/pusdatin/infodatin/infodatinpenglihatan.pdf.

Kementerian Kesehatan RI. (2017, Oktober 12). Kementerian Kesehatan Republik Indonesia. Retrieved from Menkes Luncurkan Peta Jalan Penanggulangan Gangguan Pengelihatan: http://www.depkes.go.id/article/view/17101200004/minister-of-health-launches-road-mapto-visual-impairment-handling.html.

Rumondor, N., \& Rares, L. (2014). Hubungan Kelainan Refraksi Dengan Prestasi Belajar. Jurnal EClinic (Ecl), 2(1), 1-6. Retrieved Juli 30, 2018, from https://ejournal.unsrat.ac.id/index.php/eclinic/article/view/3609/3137.

Suyasa, I., Rahayuni, I., Ariani, S., \& Harditya, K. (2017). Pemeriksaan Kesehatan dan Pengobatan Gratis Berbasis Fisik, Psikologi. JURNAL PARADHARMA , 1(2), 109-114. Retrieved July 22,2018 , from http://jurnal.undhirabali.ac.id/index.php/para_dharma/article/download/326/294.

WHO. (2017, Oktober 11 ). World Health Organization: Blindness and visual impairment. Retrieved from Blindness and visual impairment: http://www.who.int/news-room/factsheets/detail/blindness-and-visual-impairment. 